Article

\title{
Trimethylamine Sensors Based on Au-Modified Hierarchical Porous Single-Crystalline ZnO Nanosheets
}

\author{
Fanli Meng ${ }^{1}$ (D), Hanxiong Zheng ${ }^{2}$, Yufeng Sun ${ }^{2, *}$, Minqiang Li $^{3}$ and Jinhuai Liu ${ }^{3}$ \\ 1 College of Information Science and Engineering, Northeastern University, Shenyang 110819, China; \\ mengfanli@ise.neu.edu.cn \\ 2 Department of Mechanical and Automotive Engineering, Anhui Polytechnic University, Wuhu 241000, \\ China; hxzheng666@163.com \\ 3 Nanomaterials and Environment Detection Laboratory, Institute of Intelligent Machines, Chinese Academy \\ of Sciences, Hefei 230031, China; mqli@iim.ac.cn (M.L.); jhliu@iim.ac.cn (J.L.) \\ * Correspondence: sunyufeng118@126.com; Tel.: +86-553-287-1451
}

Received: 27 May 2017; Accepted: 21 June 2017; Published: 22 June 2017

\begin{abstract}
It is of great significance for dynamic monitoring of foods in storage or during the transportation process through on-line detecting trimethylamine (TMA). Here, TMA were sensitively detected by Au-modified hierarchical porous single-crystalline ZnO nanosheets (HPSCZNs)-based sensors. The HPSCZNs were synthesized through a one-pot wet-chemical method followed by an annealing treatment. Polyethyleneimine (PEI) was used to modify the surface of the HPSCZNs, and then the PEI-modified samples were mixed with Au nanoparticles (NPs) sol solution. Electrostatic interactions drive Au nanoparticles loading onto the surface of the HPSCZNs. The Au-modified HPSCZNs were characterized by X-ray diffraction (XRD), scanning electron microscopy (SEM), transmission electron microscopy (TEM) and energy dispersive spectrum (EDS), respectively. The results show that Au-modified HPSCZNs-based sensors exhibit a high response to TMA. The linear range is from 10 to $300 \mathrm{ppb}$; while the detection limit is $10 \mathrm{ppb}$, which is the lowest value to our knowledge.
\end{abstract}

Keywords: Au modification; hierarchical porous single-crystalline; trimethylamine; highly sensitive; $\mathrm{ZnO}$ nanosheets

\section{Introduction}

Freshness is one of the most important attributes to define the market value for fish in the food industry [1]. Currently, there are many technologies for fish freshness determination based on visible light spectroscopy, electrical properties, image analysis, colour, electronic noses, etc. [2]. Volatile compounds measurement is one of the vital methods to determinate fish freshness. Many volatile compounds contribute to fish odor such as ammonia, trimethylamine (TMA), hydrogen sulphide, and methylmercaptan, etc. [3]. Thereinto, TMA is an effective indicator for freshness of fish which may accelerate the decomposition of trimethyl-N-oxide in fish after death. The lowest detectable concentration of TMA was just at a ppm level so far. It was reported that $\mathrm{MoO}_{3}$ microrods [4] and punched $\mathrm{ZnO}$ nanobelt network [5]-based sensors could reach a ppb level response; however, the operating temperature of them were high. Hence, it is significant to develop a highly sensitive and low operating temperature detection method toward TMA at a trace level.

Comparing to other sensing technologies, metal oxide semiconductor sensors have been widely used due to their advantages including low cost, compact size, on-line and simple operation [6,7]. During the past years, sensing metal oxide semiconductors with different morphologies and structures have been used to fabricate gas sensors, such as punched $\mathrm{ZnO}$ nanobelt network [5], $\mathrm{SnO}_{2}-\mathrm{ZnO}$ 
nanocomposite [8], $\mathrm{TiO}_{2}-\mathrm{SnO}_{2}$ nanocomposite [9], $\mathrm{ZnO}-\mathrm{In}_{2} \mathrm{O}_{3}$ composite nanofibers [10], $\mathrm{CdO}-\mathrm{Fe}_{2} \mathrm{O}_{3}$ nanomaterials [11], and branch-like hierarchical hetero-structure $\left(\alpha-\mathrm{Fe}_{2} \mathrm{O}_{3} / \mathrm{TiO}_{2}\right)$ [12]. $\mathrm{ZnO}$ has been used as gas-sensing materials because of its unique electronic properties [13]. It has been reported that Liu et al. [14] synthesized porous single-crystalline $\mathrm{ZnO}$ nanosheets which not only exhibit high gas-sensing responses, short response time and recovery time, but also possess significant long-term stability. Haiyan Song et al. [15] synthesized three kinds of porous $\mathrm{ZnO}$ nanostructures and found that the porous single-crystalline $\mathrm{ZnO}$ nanosheets showed high gas-sensing property.

As described previously, most of the sensing materials for TMA sensors are composed of $\mathrm{ZnO}$ with different morphologies which are doped by p-type semiconductor to improve sensing properties. Hyung-SikWoo et al. [16] prepared one-dimensional $\mathrm{ZnO}-\mathrm{Cr}_{2} \mathrm{O}_{3}$ hetero-nanostructures which exhibited high selectivity and sensitivity to TMA due to the $\mathrm{p}-\mathrm{n}$ junctions. Durgajanani Sivalingam et al. [17] fabricated Mn-doped $\mathrm{ZnO}$ thin film showing a detection limit of $5 \mathrm{ppm}$, because of the increasing of the electrical conductance due to the $\mathrm{Mn}$ in $\mathrm{ZnO}$ thin film.

Introduction of noble metals into metal oxide semiconductor sensing materials has been widely used for the enhancement of gas-sensing properties [18-22]. The noble metals act as catalysts for dissociation of gas molecules into more reactive species, thereby improving the gas sensitivity [23]. In our previous work, Ag and Pt have been used to decorate porous single-crystalline $\mathrm{ZnO}$ nanosheets and $\mathrm{Au}$ has been used to modify flower-like hierarchical $\mathrm{ZnO}$ structures, which exhibited high responses to volatile organic compounds (VOCs) [24-26].

Herein, combining the advantage of noble-metal modification with the hierarchical porous single-crystalline $\mathrm{ZnO}$ structures, the Au-modified hierarchical porous single-crystalline $\mathrm{ZnO}$ nanosheets (HPSCZNs) are presented. The results show that the fabricated sensors exhibit excellent sensing performance to TMA at $260^{\circ} \mathrm{C}$.

\section{Experiment}

\subsection{Materials and Instrumentation}

Zinc acetate, Urea, Chloroauric acid, Sodium citrate and Polyethyleneimine (PEI) were all purchased from Sinopharm Chemical Reagent Co., Ltd. (Shanghai, China) and analytically pure grade.

The crystal structure of the samples was determined on X-ray diffraction (XRD, Philips X'pert PRO, Eindhoven, The Netherlands) with $\mathrm{CuK} \alpha$ radiation. Furthermore, the morphologies of the samples were characterized on field-emission scanning electron microscopy (FE-SEM, Sirion-200, FEI Company, Houston, TX, USA) and high-resolution transmission electron microscopy (HRTEM, JEM-2010, JEO, Tokyo, Japan). Energy dispersive spectroscopy (EDS) was measured on INCA X-Max 50 (Oxford Instruments, Oxford, UK). Zeta potential was measured on Potential analyzer Zeta Check (Horiba Scientific, Kyoto, Japan).

\subsection{Preparation of the HPSCZNs}

The HPSCZNs were synthesized by a one-pot wet-chemical method followed by an annealing treatment [27-29]. A typical procedure is as follows; $3.5 \mathrm{~g}$ of urea and $1 \mathrm{~g}$ of zinc acetate were dissolved into $40 \mathrm{~mL}$ of deionized water. After stirring for $30 \mathrm{~min}$, the transparent solution was sealed in a conical flask and following a heat treatment at $95^{\circ} \mathrm{C}$ for $6 \mathrm{~h}$ in an oven. Naturally cooling down, the white precipitate was then centrifuged and washed by deionized water and ethanol three times and then dried at $60^{\circ} \mathrm{C}$. Lastly, the HPSCZNs were obtained after annealing the precursor at $300{ }^{\circ} \mathrm{C}$ for $2 \mathrm{~h}$ in air in a muffle furnace.

\subsection{Synthesis of the Au Nanoparticles (NPs) and Au-Modified HPSCZNs}

Au nanoparticles (NPs) were synthesized by classical Frens method [30]. One hundred milliliters of $0.01 \% \mathrm{HAuCl}_{4}$ was heated to boil in a three-necked flask, and then $4 \mathrm{~mL}$ of sodium citrate solution was added. The Au NPs were obtained when the solution's color became red wine. 
Forty milligrams of HPSCZNs were added into $80 \mathrm{~mL}$ of polyethyleneimine (PEI) solution $(\mathrm{pH}=8)$, and then stirred for $1 \mathrm{~h}$. In addition, the PEI-modified HPSCZNs were centrifuged and washed by deionized water three times and then dried at $70{ }^{\circ} \mathrm{C}$. Finally, $40 \mathrm{mg}$ of PEI-modified HPSCZNs were added into $10 \mathrm{~mL}$ of Au NPs sol solution and stirred for $20 \mathrm{~min}$ for several times $(1,2,3,4$ and 5 times) to modify different contents of Au NPs on the HPSCZNs (\#1, \#2, \#3, \#4 and \#5 samples). Finally, they were centrifuged and coated onto ceramic tube as sensing materials. The sensing materials need to be heated at $300{ }^{\circ} \mathrm{C}$ for $2 \mathrm{~h}$ in the muffle furnace to remove the PEI before gas-sensing measurement.

\subsection{Gas-Sensing Measurement System and the Gas Sensor Fabrication}

The abridged general view of the gas-sensing measurement system is showed in Figure 1. The gas-sensing measurement system is installed in a square and closed test chamber with a volume of $1000 \mathrm{~mL}$. The sensor is placed in the center of the test chamber. The sensing materials are coated on the ceramic tube with a pair of pre-prepared gold electrodes. A piece of nichrome wire about $32 \Omega$ as heating wire is placed in the interior of the ceramic tube. There are inlets and outlets for gas flow. A Keithley 6487 picoameter/voltage source meter was used to record the change of current as well as to provide a power source. Applying a constant voltage of $1 \mathrm{~V}$ onto the electrodes between the sensing films, the current flowing through it was measured and captured. According to the gas-sensing test, a certain number of different volumes' organic vapors (e.g., ethanol, ammonia, TMA and acetone, etc.) were introduced into the test chamber from the headspace above the liquid samples by a microsyringe [31,32]. The nominal sample concentration is calculated by the following formula:

$$
C=\frac{P_{0} \times V_{\mathrm{i}}}{P_{\mathrm{a}} \times V_{\mathrm{c}}}
$$

where $P_{0}$ is the equilibrium vapor pressure at room temperature; $P_{\mathrm{a}}$ is the standard atmosphere pressure; $V_{\mathrm{i}}$ is the volume of the test gas injected by the microsyringe; $V_{\mathrm{c}}$ is the volume of the test chamber. The low concentrations of samples were prepared by diluting the vapors in a vessel before injecting them into the test chamber. At last, after injecting fresh air to release the target gas in the testing chamber, the gas-sensing measurement was finished.

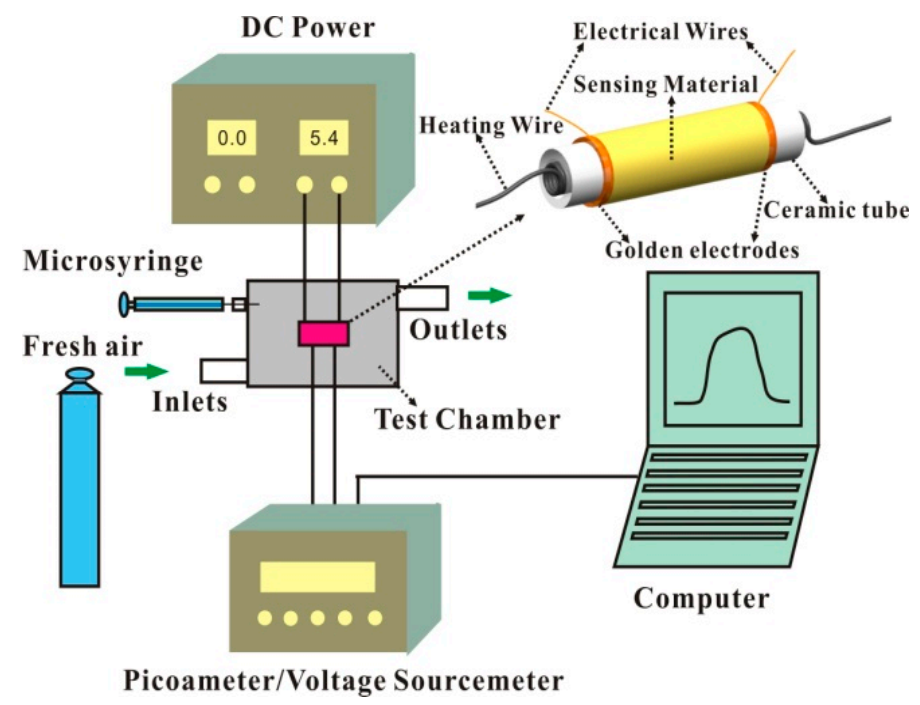

Figure 1. Schematic diagrams of the experimental system and the gas sensor.

The response of the sensor is defined as:

$$
\mathrm{S}=\mathrm{R}_{\mathrm{a}} / \mathrm{R}_{\mathrm{g}}=\mathrm{I}_{\mathrm{g}} / \mathrm{I}_{\mathrm{a}}
$$


In the equation, $\mathrm{R}_{\mathrm{a}}$ and $\mathrm{R}_{\mathrm{g}}$ are the electric resistances of the sensor in air and target gas, respectively. $I_{a}$ and $I_{g}$ are electric currents of the sensor which represent air and target gas, respectively.

The response time is defined as the time when the change of current reaches $90 \%$ of the balanced current on exposure to a target gas. Similarly, the recovery time is defined as the time reached a $90 \%$ reversal of the current.

\section{Results and Discussion}

\subsection{Characterization of the Au-Modified HPSCZNs}

Figure 2 shows XRD patterns of both the unmodified and the Au-modified HPSCZNs. All observed diffraction peaks match well with wurtzite $\mathrm{ZnO}$ (JCPDS 36-1451). Furthermore, as we can see, the diffraction peaks are narrow, suggesting that the $\mathrm{ZnO}$ crystallizes well. In addition, a weak peak of $\mathrm{Au}$ (111) appears in the pattern of the Au-modified HPSCZNs.

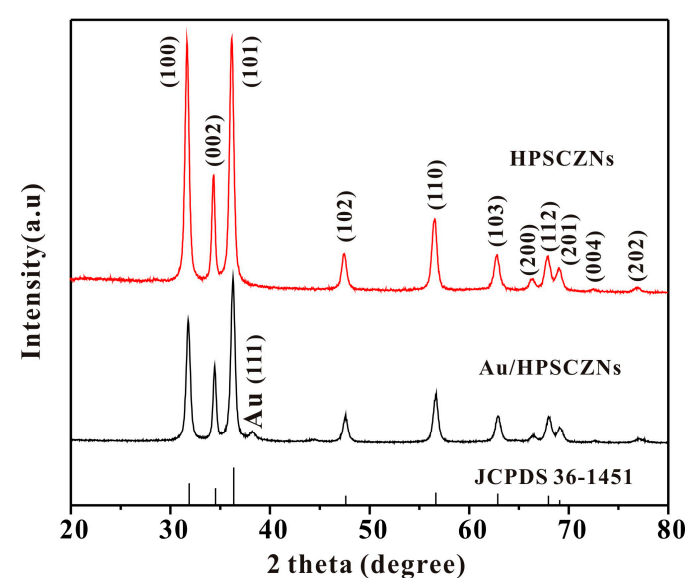

Figure 2. XRD patterns of the unmodified hierarchical porous single-crystalline $\mathrm{ZnO}$ nanosheets (HPSCZNs) (JCPDS 36-1451) and the Au-modified HPSCZNs.

The specific hierarchical, porous, single-crystalline structure of $\mathrm{ZnO}$ is further characterized by FE-SEM in Figure 3. At first, the hierarchical structure is showed in a low-magnification SEM image in Figure 3a. Many pieces of nanosheets are linked to each other, which seems like a peony with a diameter of about $15 \mu \mathrm{m}$. Figure $3 \mathrm{~b}$ is a single ultra-thin nanosheet of the "flower" in a high magnification. Figure $3 \mathrm{c}$, d show microstructures and corresponding selected area electron diffraction (SAED) pattern of the HPSCZNs investigated by TEM images. It can be seen that quantities of irregular nanosized mesopores randomly distribute over the single nanosheet. The latter consists of a series of well-ordered bright dots suggesting a single-crystalline structure.

Figure 4 shows the characteristics of the Au-modified HPSCZNs. Figure 4a shows the SEM image of a nanosheet loading with uniform Au NPs. Figure $4 b, c$ are the TEM and HRTEM images of Au-modified HPSCZNs, which shows that Au NPs adsorb on the surface of the ZnO. The clear and coherent lattice fringes of $\mathrm{ZnO}$ are also observed. The lattice spacing of $0.26 \mathrm{~nm}$ can be indexed to the (002) planes of the hexagonal phase of $\mathrm{ZnO}$. Au NPs can be combined with $\mathrm{ZnO}$ through the electrostatic interactions, since citric acid carries negative charges while PEI carries positive charges. Figure 4d is the EDS spectrum of Au-modified HPSCZNs, which shows that the as-synthesized porous products compose of element $\mathrm{Zn}, \mathrm{O}$ and $\mathrm{Au}$. 


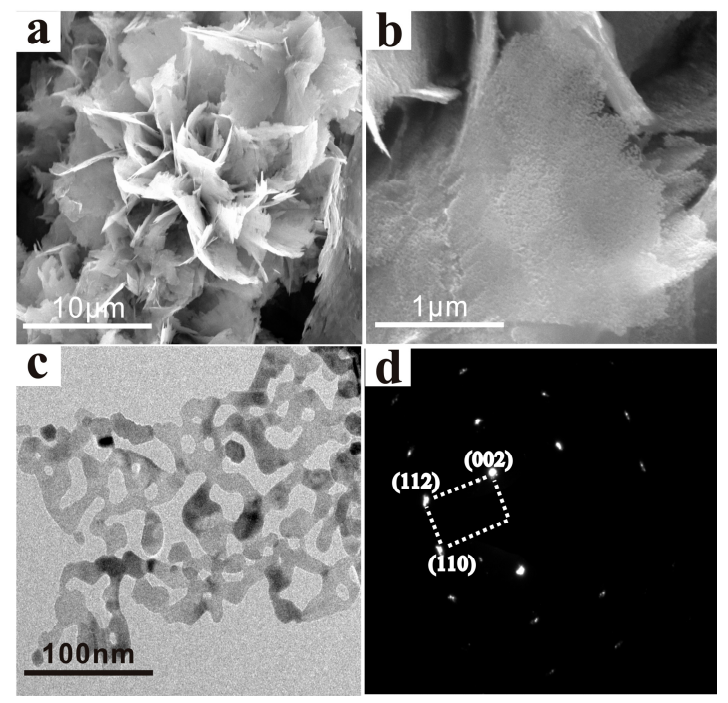

Figure 3. (a,b) SEM images, (c) TEM image and (d) corresponding SAED pattern of HPSCZNs.

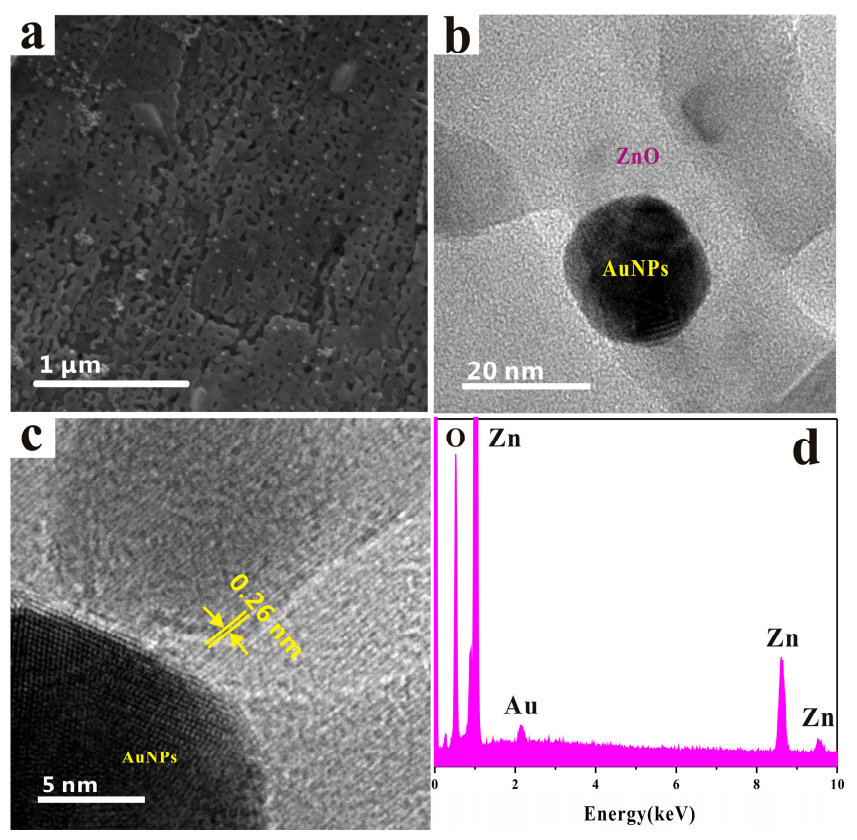

Figure 4. (a) SEM image, (b) TEM image, (c) lattice-resolved high-resolution transmission electron microscopy (HRTEM) image and (d) energy dispersive spectroscopy (EDS) spectrum of the Au-modified HPSCZNs.

\subsection{Formation Process of Au-Modified HPSCZNs}

Schematic illustration of the formation process of the Au-modified HPSCZNs are shown in Figure 5. Briefly, the formation process of Au-modified HPSCZNs contains three steps: the formation of the precursor $\left(\mathrm{Zn}_{4} \mathrm{CO}_{3}(\mathrm{OH})_{6} \cdot \mathrm{H}_{2} \mathrm{O}\right)$, the annealing treatment of the precursor and the modification of $\mathrm{Au}$ NPs. 


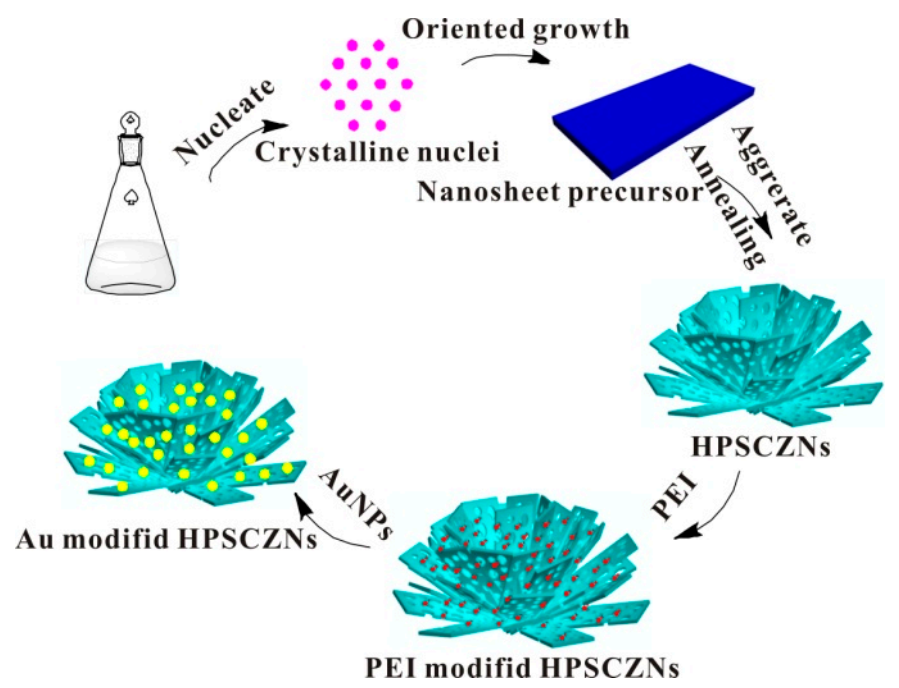

Figure 5. Schematic illustration of the formation process of the Au-modified HPSCZNs.

Firstly, crystalline nuclei form in the solution of zinc salt and urea, and then nuclei grow up via Ostwald ripening. Owing to the intrinsic anisotropic character of hexagonal structure, the aggregations would rearrange themselves and grow up along the c-axis to decrease the energy of the system during that process [33]. Chemical reactions of the precursor formation mechanism are as follows [34]:

$$
\begin{gathered}
\mathrm{CO}\left(\mathrm{NH}_{2}\right)_{2}+3 \mathrm{H}_{2} \mathrm{O} \rightarrow \mathrm{CO} \uparrow+2 \mathrm{NH}_{4} \mathrm{OH} \\
\mathrm{NH}_{4} \mathrm{OH} \rightarrow \mathrm{NH}_{4}^{+}+\mathrm{OH}^{-} \\
4 \mathrm{Zn}^{2+}+\mathrm{CO}_{2}+6 \mathrm{OH}^{-}+2 \mathrm{H}_{2} \mathrm{O} \rightarrow \mathrm{Zn}_{4} \mathrm{CO}_{3}(\mathrm{OH})_{6} \bullet \mathrm{H}_{2} \mathrm{O}+2 \mathrm{H}^{+}
\end{gathered}
$$

The precursor decomposes to release $\mathrm{CO}_{2}$ and $\mathrm{H}_{2} \mathrm{O}$ under annealing at $300{ }^{\circ} \mathrm{C}$ as the following equation:

$$
\mathrm{Zn}_{4} \mathrm{CO}_{3}(\mathrm{OH})_{6} \mathrm{H}_{2} \mathrm{O} \rightarrow 4 \mathrm{ZnO}+\mathrm{CO}_{2} \uparrow+4 \mathrm{H}_{2} \mathrm{O} \uparrow
$$

As showed in Figure 6, Zeta potential of HPSCZNs are all negative when $\mathrm{pH}$ changes from 6 to 11. When modified with Au NPs, Zeta potential changes to positive as $\mathrm{pH}$ is lower than 9.5.

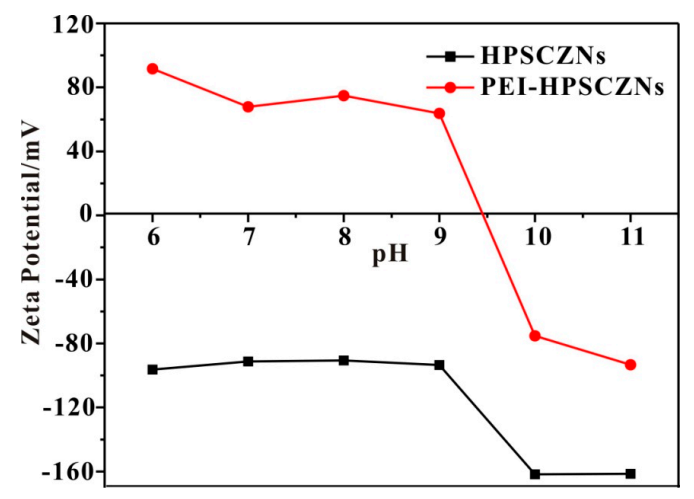

Figure 6. Relationship between Zeta potential of HPSCZNs and PEI-HPSCZN with different pH value.

When mixing HPSCZNs with PEI aqueous solution, electrostatic interactions enable PEI loading on the surface of HPSCZNs. In this condition, surface charges of the HPSCZNs are adjusted to positive. The Au NPs are negative charged due to the citric acid on its surface. 


\subsection{Operating Temperature of Au-Modified HPSCZNs}

Reactions between target gases and the adsorbed oxygen species on material surface is related to the activity of the adsorbed oxygen species. At different temperatures, there are two types of adsorbed oxygen species, one is molecular ion $\left(\mathrm{O}_{2}{ }^{-}\right)$, another is atomic ions $\left(\mathrm{O}^{-}, \mathrm{O}^{2-}\right)$. The atomic form dominates above $150{ }^{\circ} \mathrm{C}$, while molecular species work at lower temperature [35]. Figure 7 shows the plots of the response versus working temperature of the Au-modified HPSCZNs and the unmodified HPSCZNs-based sensors to 30 ppm of TMA. As we can see, the Au-modified HPSCZNs sensor exhibits different responses as shown in Figure $7 \mathrm{a}$. The sensitivity is highest at $260^{\circ} \mathrm{C}$, which is lower than the unmodified HPSCZNs sensor showed in Figure 7b, which is caused by the Au modification [36].

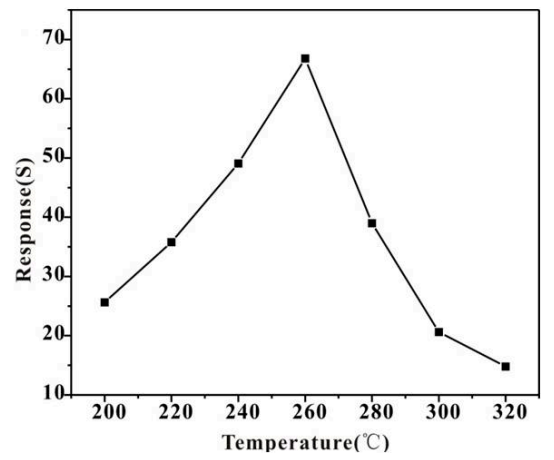

(a)

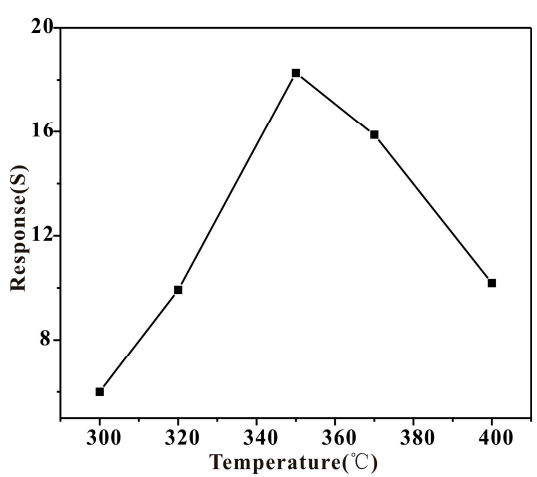

(b)

Figure 7. Operating temperature of (a) the Au-modified HPSCZNs and (b) the unmodified HPSCZNs-based sensors to $30 \mathrm{ppm}$ of trimethylamine (TMA).

\subsection{Gas-Sensing Property of Different Contents of Au NPs-Modified HPSCZNs}

Figure 8 shows the response curves of HPSCZNs with different contents of Au NPs modification to $100 \mathrm{ppb}$ of TMA. In the modification process, PEI-modified HPSCZNs were centrifuged and washed by deionized water. If content of PEI was too high, Au NPs would aggregate and then the improvement of sensing properties would be poor. Therefore, the content of PEI is also needed to be proper. The greatest factor that influences sensitivity is the contents of Au NPs. From the responses, it can be observed that sample \#3 possesses the highest response, which means that there are times that Au NPs modification is optimal in the synthesis process. That is because the Au NPs could aggregate together when the Au NPs modification is overdosed, which makes the response reduce.

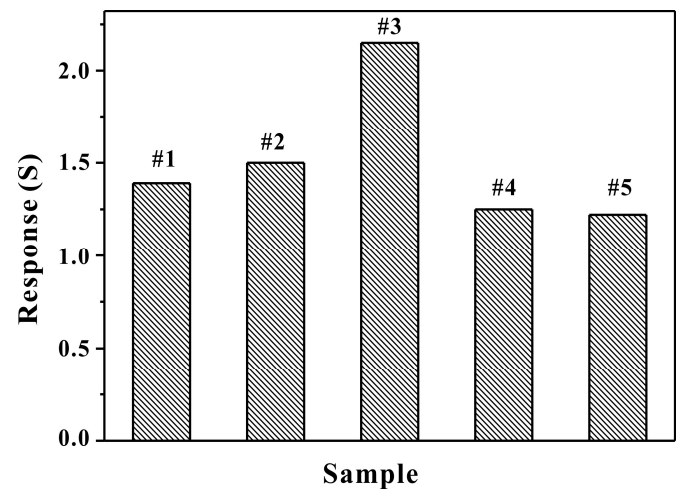

Figure 8. Response curves of the HPSCZNs sensor with different contents of Au NPs to $100 \mathrm{ppb}$ of TMA. 


\subsection{Comparison of Unmodified and Au-Modified HPSCZNs Sensors to TMA}

In order to investigate gas properties of unmodified and Au-modified HPSCZNs sensors, response curves of them to TMA is shown in Figure 9. It is clear that the response curve of the Au-modified HPSCZNs sensor is higher than that of the unmodified HPSCZNs sensor to $30 \mathrm{ppm}$ TMA. The response is 5.9 and the response and recovery times of them are $21 \mathrm{~s}$ and $70.5 \mathrm{~s}$, respectively. The response of the modified one is 65.8 and the response and recovery times are $3.3 \mathrm{~s}$ and $64 \mathrm{~s}$, respectively. The Au-modified HPSCZNs sensor processes higher response and shorter response and recovery times compared to the one without modification, which might be relevant to modification of Au NPs.

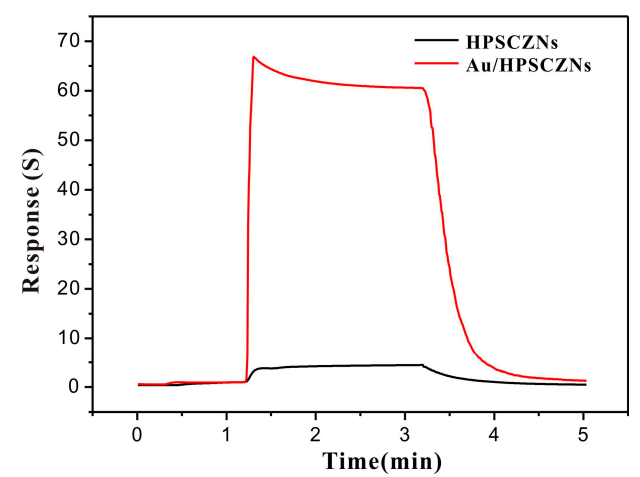

Figure 9. Response curves of the unmodified and the Au-modified HPSCZNs sensors to 30 ppm of TMA at $260{ }^{\circ} \mathrm{C}$.

\subsection{Gas-Sensing Property of the Au-Modified HPSCZNs Sensor to TMA}

The responses of the Au-modified HPSCZNs to TMA are shown in Figure 10. Figure 10a shows the real-time response curve of the sensor to different concentrations of TMA. Obviously, the responses of the sensor increase with TMA concentration. At the beginning, the adsorption reaction dominates the dynamic process and desorption interaction appears gradually and tends to be stable ultimately. The response linearly increases in the range from 10 to $300 \mathrm{ppb}$ as shown in Figure 10b. The lowest detection concentration is $10 \mathrm{ppb}$, which is an extremely low level to our knowledge.

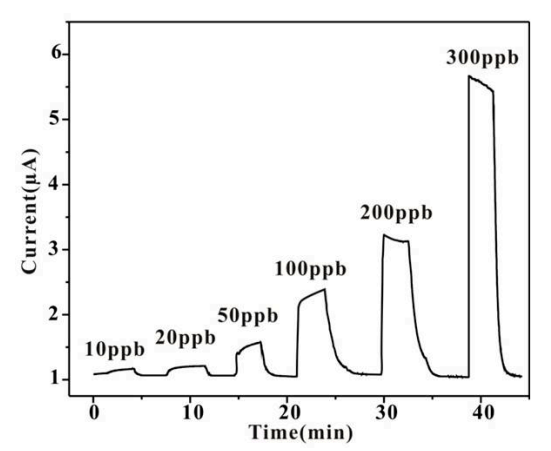

(a)

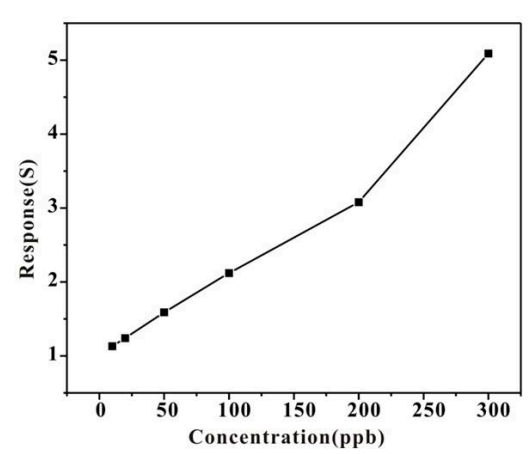

(b)

Figure 10. (a) Responses of the Au-modified HPSCZNs structures to different concentrations of TMA and $(\mathbf{b})$ the corresponding calibration curve.

\subsection{Selectivity and Stability of the Au-Modified HPSCZNs Sensors}

It was reported that $\mathrm{ZnO}$ structure gas sensors showed response to many gases: $\mathrm{CH}_{3} \mathrm{COCH}_{3}, \mathrm{CO}$, $\mathrm{C}_{2} \mathrm{H}_{5} \mathrm{OH}, \mathrm{H}_{2} \mathrm{~S}, \mathrm{HCHO}$, etc. [37]. Nevertheless, response comparison of $30 \mathrm{ppm}$ TMA and other gases at $260{ }^{\circ} \mathrm{C}$ suggest that the Au-modified HPSCZNs sensor have high selectivity to TMA as shown in Figure 11. Response of TMA is two times higher than that of ammonia. The reactivity of the reducing 
gases determines the sensor's sensitivity, so the mechanism of high selectivity to TMA can be explained from the bond energy. The molecular structures and the bond energies of many gases are showed in Table 1 [38]. The bond energy of $\mathrm{H}-\mathrm{CH}_{2}$ with the highest response is only $380.7 \mathrm{KJ} / \mathrm{mol}$, which is smaller than any other organic gases in the table. Therefore, $\mathrm{H}-\mathrm{CH}_{2}$ can be easily broken to take part in adsorption reaction with sensing material; all of this results in the high selectivity of TMA.

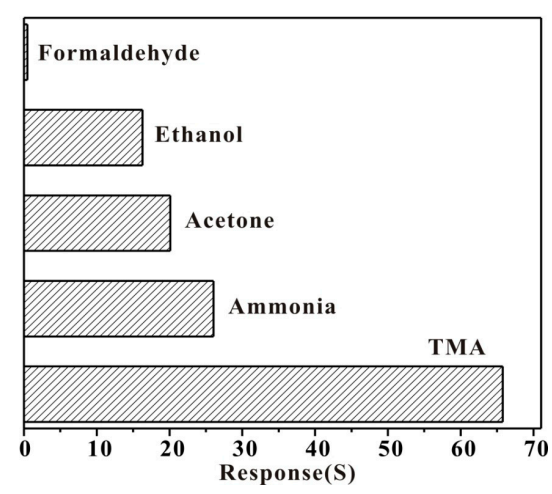

Figure 11. Response comparison of $30 \mathrm{ppm}$ of TMA and $30 \mathrm{ppm}$ of other volatile organic compounds (VOCs) at $260^{\circ} \mathrm{C}$.

Table 1. Properties of gas molecules.

\begin{tabular}{cccc}
\hline Gas Type & Molecular Structures & Bond & Bond Energy (KJ/mol) \\
\hline Formaldehyde & & $\mathrm{H}-\mathrm{CHO}$ & 436 \\
& & $\mathrm{H}-\mathrm{OCH}_{2} \mathrm{CH}_{3}$ & 436 \\
Ethanol & $\mathrm{H}-\mathrm{CH}_{2}$ & 473 \\
& $\mathrm{H}-\mathrm{CH}$ & 452 \\
Acetone & $\mathrm{H}-\mathrm{CH}_{2} \mathrm{OCH}_{3}$ & 393 \\
Ammonia & $\mathrm{H}-\mathrm{NH}_{2}$ & 435 \\
TMA & & $\mathrm{H}-\mathrm{CH}_{2}$ & 380.7 \\
\hline
\end{tabular}

Stability has been investigated by the gas response of Au-modified HPSCZNs sensors to $100 \mathrm{ppb}$ of TMA within 21 days as shown in Figure 12. During the experimental process, the response of the Au-modified HPSCZNs sensor hardly floats up and down, indicating that the Au-modified HPSCZNs sensors exhibit a good stability.

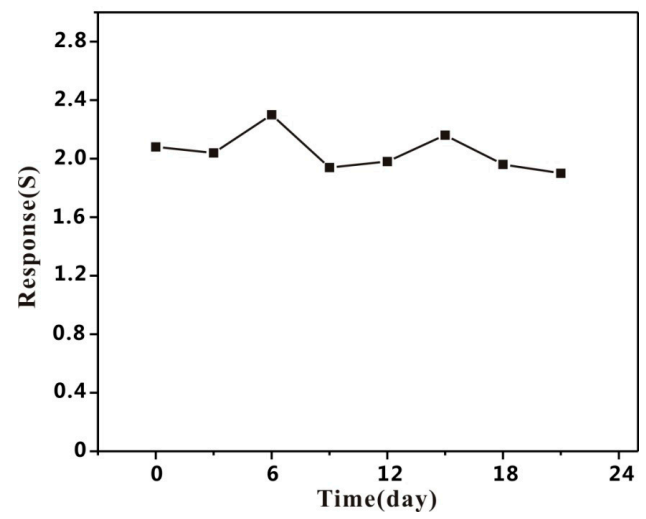

Figure 12. Stability of the Au-modified HPSCZNs sensor to 100 ppb of TMA. 


\subsection{Sensing Mechanism of Au-Modified HPSCZNs}

The Au-modified HPSCZNs sensor becomes more sensitive due to the mesopores on each nanosheet, hierarchical morphology, single-crystalline structure and Au NPs modification. On one hand, mesopores enlarge specific surface area of HPSCZNs and offer plenty of active sites for surface chemical reactions; on the other hand, hierarchical structure enables gases to diffuse into the film and the inner of the material by molecular diffusion [39-41]. Given as a Knudsen flow, the diffusion coefficient can be defined by the following equation [42]:

$$
\mathrm{D}_{\mathrm{K}}=\frac{\varepsilon \mathrm{d}}{3 \tau}\left(\frac{8 \mathrm{RT}}{\pi \mathrm{M}}\right)^{\frac{1}{2}}
$$

where $D_{k}, \varepsilon, d, \tau, R, T$ and $M$ are Knudsen diffusion coefficients, dimensionless porosity, dimensionless tortuosity, pore diameter, gas constant, temperature and molar mass, respectively. Obviously, the gas diffusion is proportional to pore diameter and porosity presented in the equation, the pore diameter of HPSCZNs is around $30 \mathrm{~nm}$; smaller and less overlapped necks interact with test gases, which results from a greater porosity [43]. On the basis of these two advantages, gas molecules are permitted to diffuse into the film rapidly. What is more, single-crystalline structure also plays a significant role for improving sensitivity. As is known to all, electrons need to overcome boundary barrier between particles when they transport from one side to another; it would obviously decrease the sensitivity. The as-prepared products that contain lots of single-crystalline $\mathrm{ZnO}$ nanosheet structures that comply with the grain boundary barrier model are equivalent to reduce particle boundary barriers, and further increase the sensitivity and stability. Lastly, Au NPs modification acts as the most critical role to improve the sensitivity. It not only possesses high catalytic activity but also increases the depth of the space-charge layers [44]. When the sensor exposes to air, Au NPs accelerate $\mathrm{O}_{2}$ which is adsorbed on the surface of HPSCZNs capturing electrons to form $\mathrm{O}_{2}{ }^{-}, \mathrm{O}^{-}$and $\mathrm{O}^{2-}$ ions.

\section{Conclusions}

In conclusion, HPSCZNs were successfully synthesized. Under the optimal operating temperature of $260^{\circ} \mathrm{C}$, the Au-modified HPSCZNs sensor exhibits a high response to TMA. The linear range is 10-300 ppb; while the lowest detection is $10 \mathrm{ppb}$. The Au-modified HPSCZNs, combining with the advantages of high response, long-term stability, low power consumption and cost, may provide a novel pathway to make gas sensors for the detection of the freshness of fish and some other foods.

Acknowledgments: This work was supported by the National Basic Research Program of China (2013CB934304), the National Natural Science Foundation of China (61673367, 61374017, 61573334 and 31571567) and the Key Technologies R \& D Program of Anhui Province (1501021005).

Author Contributions: Fanli Meng andYufeng Sun conceived and designed the experiments; Hanxiong Zheng and Fanli Meng performed the experiments; Fanli Meng, Hanxiong Zheng, Yufeng Sun and Jinhuai Liu analyzed the data; Minqiang Li contributed reagents/materials/analysis tools; Fanli Meng and Hanxiong Zheng wrote the paper.

Conflicts of Interest: The authors declare no conflict of interest.

\section{References}

1. Garcia, M.R.; Cabo, M.L.; Herrera, J.R.; Ramilo-Fernandez, G.; Alonso, A.A.; Balsa-Canto, E. Smart sensor to predict retail fresh fish quality under ice storage. J. Food Eng. 2017, 197, 87-97. [CrossRef]

2. Olafsdottir, G.; Nesvadba, P.; Di Natale, C.; Careche, M.; Oehlenschager, J.; Tryggvadottir, S.V.; Schubring, R.; Kroeger, M.; Heia, K.; Esaiassen, M.; et al. Multisensor for fish quality determination. Trends Food Sci. Tech. 2004, 15, 86-93. [CrossRef]

3. Cheng, J.H.; Sun, D.W.; Zeng, X.A.; Liu, D. Recent Advances in Methods and Techniques for Freshness Quality Determination and Evaluation of Fish and Fish Fillets: A Review. Crit. Rev. Food Sci. 2015, 55, 1012-1025. [CrossRef] [PubMed] 
4. Chu, X.F.; Liang, S.M.; Sun, W.Q.; Zhang, W.B.; Chen, T.Y.; Zhang, Q.F. Trimethylamine sensing properties of sensors based on MoO3 microrods. Sens. Actuators B Chem. 2010, 148, 399-403. [CrossRef]

5. Na, C.W.; Park, S.Y.; Lee, J.H. Punched ZnO nanobelt networks for highly sensitive gas sensors. Sens. Actuators B Chem. 2012, 174, 495-499. [CrossRef]

6. Meng, F.L.; Li, H.H.; Kong, L.T.; Liu, J.Y.; Jin, Z.; Li, W.; Jia, Y.; Liu, J.H.; Huang, X.J. Parts per billion-level detection of benzene using $\mathrm{SnO}_{2}$ /graphene nanocomposite composed of sub-6 nm $\mathrm{SnO}_{2}$ nanoparticles. Anal. Chim. Acta 2012, 736, 100-107. [CrossRef] [PubMed]

7. Sun, Y.F.; Huang, X.J.; Meng, F.L.; Liu, J.H. Study of influencing factors of dynamic measurements based on $\mathrm{SnO}_{2}$ gas sensor. Sensors 2004, 4, 95-104. [CrossRef]

8. Zhang, W.H.; Zhang, W.D. Fabrication of $\mathrm{SnO}_{2}-\mathrm{ZnO}$ nanocomposite sensor for selective sensing of trimethylamine and the freshness of fishes. Sens. Actuators B Chem. 2008, 134, 403-408. [CrossRef]

9. Jung, J.Y.; Lee, C.S. Characteristics of the $\mathrm{TiO}_{2} / \mathrm{SnO}_{2}$ thick film semiconductor gas sensor to determine fish freshness. J. Ind. Eng. Chem. 2011, 17, 237-242. [CrossRef]

10. Lee, C.S.; Kim, I.D.; Lee, J.H. Selective and sensitive detection of trimethylamine using $\mathrm{ZnO} \mathrm{In}_{2} \mathrm{O}_{3}$ composite nanofibers. Sens. Actuators B Chem. 2013, 181, 463-470. [CrossRef]

11. Chu, X.F.; Liang, S.M.; Chen, T.Y.; Zhang, Q.F. Trimethylamine sensing properties of $\mathrm{CdO}_{-}-\mathrm{Fe}_{2} \mathrm{O}_{3}$ nano-materials prepared using co-precipitation method in the presence of PEG400. Mater. Chem. Phys. 2010, 123, 396-400. [CrossRef]

12. Lou, Z.; Li, F.; Deng, J.A.; Wang, L.L.; Zhang, T. Branch-like Hierarchical Heterostructure (alpha- $\mathrm{Fe}_{2} \mathrm{O}_{3} / \mathrm{TiO}_{2}$ ): A Novel Sensing Material for Trimethylamine Gas Sensor. Acs Appl. Mater. Interfaces 2013, 5, 12310-12316. [CrossRef] [PubMed]

13. Jin, Z.; Zhang, Y.X.; Meng, F.L.; Jia, Y.; Luo, T.; Yu, X.Y.; Wang, J.; Liu, J.H.; Huang, X.J. Facile synthesis of porous single crystalline $\mathrm{ZnO}$ nanoplates and their application in photocatalytic reduction of $\mathrm{Cr}(\mathrm{VI})$ in the presence of phenol. J. Hazard. Mater. 2014, 276, 400-407. [CrossRef] [PubMed]

14. Liu, J.Y.; Guo, Z.; Meng, F.L.; Luo, T.; Li, M.Q.; Liu, J.H. Novel porous single-crystalline ZnO nanosheets fabricated by annealing $\mathrm{ZnS}(\mathrm{en})_{0.5}$ (en = ethylenediamine) precursor. Application in a gas sensor for indoor air contaminant detection. Nanotechnology 2009, 20. [CrossRef] [PubMed]

15. Song, H.Y.; Yang, H.; Ma, X.C. A comparative study of porous $\mathrm{ZnO}$ nanostructures synthesized from different zinc salts as gas sensor materials. J. Alloy. Compd. 2013, 578, 272-278. [CrossRef]

16. Woo, H.S.; Na, C.; Kim, I.D.; Lee, J.H. Highly sensitive and selective trimethylamine sensor using one-dimensional $\mathrm{ZnO}-\mathrm{Cr}_{2} \mathrm{O}_{3}$ hetero-nanostructures. Nanotechnology 2012, 23. [CrossRef] [PubMed]

17. Sivalingam, D.; Gopalakrishnan, J.B.; Rayappan, J.B.B. Structural, morphological, electrical and vapour sensing properties of Mn doped nanostructured $\mathrm{ZnO}$ thin films. Sens. Actuators B Chem. 2012, 166, 624-631. [CrossRef]

18. Joshi, R.K.; Hu, Q.; Am, F.; Joshi, N.; Kumar, A. Au Decorated Zinc Oxide Nanowires for CO Sensing. J. Phys. Chem C 2009, 113, 16199-16202. [CrossRef]

19. Tamaekong, N.; Liewhiran, C.; Wisitsoraat, A.; Phanichphant, S. Sensing Characteristics of Flame-Spray-Made Pt/ZnO Thick Films as $\mathrm{H}_{2}$ Gas Sensor. Sensors 2009, 9, 6652-6669. [CrossRef] [PubMed]

20. Simon, Q.; Barreca, D.; Gasparotto, A.; Maccato, C.; Tondello, E.; Sada, C.; Comini, E.; Devi, A.; Fischer, R.A. $\mathrm{Ag} / \mathrm{ZnO}$ nanomaterials as high performance sensors for flammable and toxic gases. Nanotechnology 2012, 23. [CrossRef] [PubMed]

21. Zhu, G.X.; Liu, Y.J.; Xu, H.; Chen, Y.; Shen, X.P.; Xu, Z. Photochemical deposition of Ag nanocrystals on hierarchical $\mathrm{ZnO}$ microspheres and their enhanced gas-sensing properties. Crystengcomm 2012, 14, 719-725. [CrossRef]

22. Meng, F.L.; Guo, Z.; Huang, X.J. Graphene-based hybrids for chemiresistive gas sensors. TrAC Trends Anal. Chem. 2015, 68, 37-47. [CrossRef]

23. Kim, S.S.; Park, J.Y.; Choi, S.W.; Kim, H.S.; Na, H.G.; Yang, J.C.; Kim, H.W. Significant enhancement of the sensing characteristics of $\operatorname{In}_{2} \mathrm{O}_{3}$ nanowires by functionalization with Pt nanoparticles. Nanotechnology 2010, 21. [CrossRef] [PubMed] 
24. Meng, F.L.; Hou, N.N.; Jin, Z.; Sun, B.; Guo, Z.; Kong, L.T.; Xiao, X.H.; Wu, H.; Li, M.Q.; Liu, J.H. Ag-decorated ultra-thin porous single-crystalline $\mathrm{ZnO}$ nanosheets prepared by sunlight induced solvent reduction and their highly sensitive detection of ethanol. Sens. Actuators B Chem. 2015, 209, 975-982. [CrossRef]

25. Meng, F.L.; Hou, N.N.; Jin, Z.; Sun, B.; Li, W.Q.; Xiao, X.H.; Wang, C.; Li, M.Q.; Liu, J.H. Sub-ppb detection of acetone using Au-modified flower-like hierarchical ZnO structures. Sens. Actuators B Chem. 2015, 219, 209-217. [CrossRef]

26. Gu, C.P.; Huang, H.H.; Huang, J.R.; Jin, Z.; Zheng, H.X.; Liu, N.; Li, M.Q.; Liu, J.H.; Meng, F.L. Chlorobenzene sensor based on Pt-decorated porous single-crystalline ZnO nanosheets. Sens. Actuators A Phys. 2016, 252, 96-103. [CrossRef]

27. Meng, F.L.; Ge, S.; Jia, Y.; Sun, B.; Sun, Y.F.; Wang, C.; Wu, H.; Jin, Z.; Li, M.Q. Interlaced nanoflake-assembled flower-like hierarchical $\mathrm{ZnO}$ microspheres prepared by bisolvents and their sensing properties to ethanol. J. Alloy Compd. 2015, 632, 645-650. [CrossRef]

28. Meng, F.L.; Hou, N.N.; Ge, S.; Sun, B.; Jin, Z.; Shen, W.; Kong, L.T.; Guo, Z.; Sun, Y.F.; Wu, H.; et al. Flower-like hierarchical structures consisting of porous single-crystalline $\mathrm{ZnO}$ nanosheets and their gas sensing properties to volatile organic compounds (VOCs). J. Alloy Compd. 2015, 626, 124-130. [CrossRef]

29. Hou, N.N.; Jin, Z.; Sun, B.; Sun, Y.F.; Shen, W.; Guo, Z.; Kong, L.T.; Li, M.Q.; Meng, F.L. New Strategy for Rapid Detection of the Simulants of Persistent Organic Pollutants Using Gas Sensor Based on 3-D Porous Single-Crystalline ZnO Nanosheets. IEEE Sens. J. 2015, 15, 3668-3674. [CrossRef]

30. Frens, G. Controlled Nucleation for the Regulation of the Particle Size in Monodisperse Gold Suspensions. Nat. Phys. Sci. 1973, 241, 20-22. [CrossRef]

31. Pavluchenko, A.S.; Mamykin, A.V.; Kukla, A.L.; Konoshchuk, N.V.; Posudievsky, O.Y.; Koshechko, V.G. Estimation of multicomponent organic solvent vapor mixture composition with electroconducting polymer chemiresistors. Sens. Actuators B Chem. 2016, 232, 203-218. [CrossRef]

32. Wang, Q.J.; Liu, F.M.; Lin, J.; Lu, G.Y. Gas-sensing properties of In-Sn oxides composites synthesized by hydrothermal method. Sens. Actuators B Chem. 2016, 234, 130-136. [CrossRef]

33. Kwon, T.H.; Park, S.H.; Ryu, J.Y.; Choi, H.H. Zinc oxide thin film doped with $\mathrm{Al}_{2} \mathrm{O}_{3}, \mathrm{TiO}_{2}$ and $\mathrm{V}_{2} \mathrm{O}_{5}$ as sensitive sensor for trimethylamine gas. Sens. Actuators B Chem. 1998, 46, 75-79.

34. Chang, J.; Ahmad, M.Z.; Wlodarski, W.; Waclawik, E.R. Self-Assembled 3D ZnO Porous Structures with Exposed Reactive $\{0001\}$ Facets and Their Enhanced Gas Sensitivity. Sensors 2013, 13, 8445-8460. [CrossRef] [PubMed]

35. Barsan, N.; Weimar, U. Conduction model of metal oxide gas sensors. J. Electroceram. 2001, 7, $143-167$. [CrossRef]

36. Guo, J.; Zhang, J.; Zhu, M.; Ju, D.X.; Xu, H.Y.; Cao, B.Q. High-performance gas sensor based on ZnO nanowires functionalized by Au nanoparticles. Sens. Actuators B Chem. 2014, 199, 339-345. [CrossRef]

37. Luo, X.J.; Lou, Z.; Wang, L.L.; Zheng, X.J.; Zhang, T. Fabrication of flower-like ZnO nanosheet and nanorod-assembled hierarchical structures and their enhanced performance in gas sensors. New J. Chem. 2014, 38, 84-89. [CrossRef]

38. Liu, Z.T.; Fan, T.X.; Zhang, D.; Gong, X.L.; Xu, J.Q. Hierarchically porous ZnO with high sensitivity and selectivity to $\mathrm{H}(2) \mathrm{S}$ derived from biotemplates. Sens. Actuators B Chem. 2009, 136, 499-509. [CrossRef]

39. Li, H.H.; Meng, F.L.; Liu, J.Y.; Sun, Y.F.; Jin, Z.; Kong, L.T.; Hu, Y.J.; Liu, J.H. Synthesis and gas sensing properties of hierarchical meso-macroporous $\mathrm{SnO}_{2}$ for detection of indoor air pollutants. Sens. Actuators $B$ Chem. 2012, 166, 519-525. [CrossRef]

40. Matsunaga, N.; Sakai, G.; Shimanoe, K.; Yamazoe, N. Formulation of gas diffusion dynamics for thin film semiconductor gas sensor based on simple reaction-diffusion equation. Sens. Actuators B Chem. 2003, 96, 226-233. [CrossRef]

41. Sakai, G.; Matsunaga, N.; Shimanoe, K.; Yamazoe, N. Theory of gas-diffusion controlled sensitivity for thin film semiconductor gas sensor. Sens. Actuators B Chem. 2001, 80, 125-131. [CrossRef]

42. Yang, J.H.; Cermakova, J.; Uchytil, P.; Hamel, C.; Seidel-Morgenstern, A. Gas phase transport, adsorption and surface diffusion in a porous glass membrane. Catal. Today 2005, 104, 344-351. [CrossRef] 
43. Korotcenkov, G. The role of morphology and crystallographic structure of metal oxides in response of conductometric-type gas sensors. Mat. Sci. Eng. R 2008, 61, 1-39. [CrossRef]

44. Liu, C.; Kuang, Q.; Xie, Z.X.; Zheng, L.S. The effect of noble metal (Au, Pd and Pt) nanoparticles on the gas sensing performance of $\mathrm{SnO}_{2}$-based sensors: A case study on the $\{221\}$ high-index faceted $\mathrm{SnO}_{2}$ octahedra. CrystEngComm 2015, 17, 6308-6313. [CrossRef]

(). (1)

(C) 2017 by the authors. Licensee MDPI, Basel, Switzerland. This article is an open access article distributed under the terms and conditions of the Creative Commons Attribution (CC BY) license (http:/ / creativecommons.org/licenses/by/4.0/). 